\title{
Combined Endoscopic \& Radiologic Intervention For Management Of Acute Perforated Peptic Ulcer : A Randomized Controlled Trial
}

Said Negm ( $\sim$ said.negm@outlook.com )

Zagazig University

Hatem Mohamed

Zagazig University

Ahmed Shafiq

Zagazig University

Taha AbdelKader

Ministry of Health

Adel Ismail

Ismailia Teaching Oncology Hospital

Mahmoud Yassin

Zagazig University

Bassam Mousa

Zagazig University

Mohamed Abozaid

Zagazig University

Yasser A. Orban

Zagazig University

Mazoun Al Alawi

Ministry of Health

Ahmed Farag

Zagazig University

\section{Research Article}

Keywords: peptic ulcer, stent, clipping, surgical emergency, endoscopy

Posted Date: February 2nd, 2022

DOI: https://doi.org/10.21203/rs.3.rs-1304207/v1 
License: (c) (i) This work is licensed under a Creative Commons Attribution 4.0 International License. Read Full License 


\section{Abstract}

\section{Background :}

Peptic ulcer perforation is a common and life threatening surgical emergency. The traditional , pedical omental patch is performed for the plugging of perforated peptic ulcer was first described by CellanJones in 1929. Although it is attributed to Graham, who described the use of a free graft of the omentum to repair the perforation in 1937. Many endoscopic methods have been used to treat acute perforated peptic ulcer like over the scope clips, standard endoscopic clips, endoscopic sewing and metallic stents. The main idea in endoscopic management of acute perforated peptic ulcer is early decontamination and decrease sepsis by interventional radiologic drainage.

\section{Methods:}

This study included patients who were developed acute perforated peptic ulcer manifestations and were admitted to our hospital between December 2019 to August 2021. Sample size was 100 patients divided into 2 equal groups. Endoscopic group (EG): included 50 patients who were subjected to endoscopic management. Surgical group (SG): included 50 patients who were subjected to surgical management.

\section{Results:}

Hundred patients were randomized into 2 groups: Surgery Group (SG, $n=50$ ) and Endoscopy Group (EG, $n=50$ ). Median age of patients was 36(range 27:54) and 47( range 41:50) years-old in SG and EG, respectively. Males constituted $72 \%$ and $66 \%$ in SG and EG, respectively. Median postoperative hospital stay was 1 (range: 1-2) days in EG, while in SG was 7 (range 6-8) days. Postoperative complications in SG patients were $58 \%$ in form of fever, pneumonia , leak, abdominal abcess, renal failure, incisional hernia, ( $11 \%, 5 \%, 5 \%, 3 \%, 2 \%, 3 \%$, respectively). While postoperative complications in EG patients were $24 \%$ in form of fever, pneumonia , leak, abdominal abcess, renal failure, incisional hernia, $(10 \%, 0 \%, 2 \%$, $0 \%, 0 \%, 0 \%$, respectively).

\section{Conclusion:}

combined endoscopic \& interventional radiology can effectively manage acute perforated peptic ulcer without need for general anesthesia, within short time, in high risk surgical patients with low incidence of morbidity \& mortality.

This study was retrospectively submitted in clinicaltrials.gov in September 2021 (NCT05051683).

\section{Introduction}

Peptic ulcer perforation is a common and life threatening surgical emergency ${ }^{(1)}$. Surgical management is the standard treatment either laparoscopic or laparotomy but still carries high morbidity (35\%) and mortality $(5-16 \%){ }^{(2)}$. The traditional, pedical omental patch is performed for the plugging of perforated 
peptic ulcer was first described by Cellan-Jones in $1929^{(3)}$. Although it is attributed to Graham, who described the use of a free graft of the omentum to repair the perforation in $1937^{(4)}$. High risk surgical patients have been treated by nasogastric tube \& suction this called Taylor's method or conservative treatment ${ }^{(5)}$. High risk surgical patients management was associated with high mortality rate so, conservative management was accompanied by a percutaneous drainage, and mortality rate was reduced to $20 \%{ }^{(6)}$. Many endoscopic methods have been used to treat acute perforated peptic ulcer like over the scope clips, standard endoscopic clips, endoscopic sewing and metallic stents ${ }^{(7)}$. The main idea in endoscopic management of acute perforated peptic ulcer is early decontamination and decrease sepsis by interventional radiologic drainage ${ }^{(8)}$.

\section{Objectives:}

To assess the effect of endoscopy over surgery in management of acute perforated peptic ulcer in reducing morbidity \& mortality rate and reducing the surgical complications.

\section{Patients And Methods}

\section{Patients}

We included all patients who developed acute perforated peptic ulcer manifestations and referred to our Emergency department between December 2019 to August 2021 with age more than 18 years old ( onset between clinical manifestations \& diagnosis \& intervention range from 12 hours to 3 days provided that patients not develop septic shock ). While patients with age below 18 years old and patients with septic shock were excluded. This prospective randomized controlled clinical trial was approved by Zagazig University Faculty of Medicine Institutional Review Board (Approval Number: 11195/20.12.2019) and performed in accordance with the code of ethics of the World Medical Association (Declaration of Helsinki) for studies involving human subjects. This study was retrospectively submitted in clinicaltrials.gov in September 2021 (NCT05051683). Written informed consent was obtained from all participants after explaining to them all the study procedures with its benefits and hazards.

Included patients were randomized at a 1:1 ratio to "Surgery Group, SG" or "Endoscopic Group" via the drawing of sealed envelopes containing computer-generated random numbers prepared by a third party before the start of the intervention. Sample size was calculated using open Epi program using the following data: confidence interval $95 \%$, power of test $80 \%$, ratio of unexposed/exposed 1 , percent of patients with successful management of acute perforated peptic ulcer by surgical intervention $50 \%$ and those with successful management by endoscopy $99 \%$, odds ratio $99 \%$, and risk ratio 2 .

Primary and secondary outcomes were leak and mortality in each group after the intervention during the 3-months follow-up period, respectively.

\section{Diagnosis}


After full history taking and complete physical examination, acute perforated peptic ulcer was clinically suspected and then confirmed by laboratory investigations (complete blood picture, liver and kidney functions, coagulation profile), radiological imaging ( plain erect chest X-ray abdomen, abdominal US to know amount of contamination, CT abdomen with oral and I.V contrast to know site of perforation ).

\section{Intervention}

Patients, randomized to the endoscopy group, first assess the site \& size of perforation then underwent endoscopic stenting (fully covered self-expanded metallic stent, FCSEMS) this for duodenal ulcer only due to narrow lumen while in gastric ulcer (due to capacious cavity) in additional to FCSEMS usage we also used endoscopic Over-The-Scope Clipping (OTSC, Ovesco Endoscopy AG, Tubingen, Germany) in narrow perforation (less than $1 \mathrm{~cm}$ ), endoscopic suturing (OverStitch (36), Apollo Endo-surgery, TX, United States) in wide perforation ( from $1 \mathrm{~cm}$ to $2 \mathrm{~cm}$ ). At same time a radiologic interventional team worked and drainage of peritoneal collection was done by 2 intra-peritoneal tube drains one was placed sub-hepatic another was placed in the pelvis under sonar gaudiness.

During postoperative day one a methylene blue test was done . and blue color was observed in the drain. Patients, randomized to the SG, underwent surgical exploration \& primary repair of perforation supported by Grham's omental patch and putting 2 intra-peritoneal tube drains one was placed sub-hepatic another was placed in the pelvis.

\section{Follow up after endoscopy and discharge from the hospital}

All patients were clinically examined, and laboratory checked during the hospital stay. Any suspected leak post repair mandated CT scan with oral and I.V contrast and upper GI endoscopy. Patients were followedup for at least 3 months post repair.

\section{Statistical analysis}

Analysis of data was performed using SPSS (Statistical Package of Social Services) version 22. Quantitative variables were described as mean $( \pm S D$, standard deviation) and median (range) according to Shapiro test of normality. Qualitative variables were described as number and percentage. Chi-square test was used to compare qualitative variables between the 2 groups. Fisher exact test was used when one expected cell or more are less than 5. Unpaired t-test was used to compare quantitative variables, in parametric data (SD $<30 \%$ of the mean). Mann Whitney test was used instead of unpaired t-test in nonparametric data (SD $>30 \%$ of the mean). The results were considered statistically significant when the significant probability was less than $0.05(P<0.05)$. P-value $<0.001$ was considered highly statistically significant (HS), and P-value $\geq 0.05$ was considered statistically insignificant (NS).

\section{Results}

The eligible 100 patients were randomized into 2 groups: SG and EG as in tables 1,2,3,4. Median age of patients was 47 with range (41:50) and 36 (27:54) years-old in EG and SG, respectively. Males 
constituted $66 \%(33 / 50)$ and $72 \%(36 / 50)$ of patients in EG and SG, respectively. All patients needed general anesthesia (figure 5) in SG patients, while in EG patients, only $6(12 \%)$ patients needed . Median operative time ( figure 1,2,3 ) was 17.5 with range (15:20) and 50 (45:60) minutes in EG and SG, respectively. The blue dye test was negative in $48(96 \%)$ \& $45(90 \%)$ patients in $E G$ and SG, respectively. The incidence of success to close the perforation was $96 \%$ (48 patients) \& 90\% (45 patients) in EG and SG, respectively. The median of postoperative hospital stay ( figure 1,2,3) was 1 with range (1:2) \& $7(6: 8)$ days in EG and SG, respectively. C-Ractive protein \& WBCs count decreased ( figure 4) in 48 (96\%) \& 45 (90\%) patients in EG and SG, respectively. Postoperative complications in SG patients were $58 \%$ in form of fever, pneumonia , leak , abdominal abcess, renal failure, incisional hernia, $(11 \%, 5 \%, 5 \%, 3 \%, 2 \%, 3 \%$, respectively). While postoperative complications in EG patients were $24 \%$ in form of fever, pneumonia, leak , abdominal abcess, renal failure, incisional hernia, $(10 \%, 0 \%, 2 \%, 0 \%, 0 \%, 0 \%$, respectively). Mortality rate was $6 \%$ ( 3 patients ) \& zero \% in SG and EG, respectively .

\section{Discussion}

Combined Endoscopic \& Radiologic intervention has become a promising tool in managing of a cute perforated peptic ulcer with different modalities such as stenting, clipping and endo-suturing combined with radiologic drainage if there was abdominal collection at the same session. The advantages of the endoscopic intervention were no need for general anesthesia in most of the cases, short operative time, short postoperative hospital stay, incidence of postoperative (incisional hernia\& seroma) is zero \%, early oral feeding , no surgical incisions at all , suitable for high risk surgical patients and high success rate.

In our study, OTSC was used in 15 patients (30\%) with only perforated gastric ulcer ( not duodenal ulcer), without clip migration or development of post-OTSC stricture over 3-months follow-up period. We started putting the clips perpendicular to the long axis of the defect. If needed, more than one clip was placed sequentially, starting at periphery of the defect towards the center. Standard clips were passed throughthe-scope to achieve superficial tissue apposition engaging the mucosa and submucosa (with 1.2-mmwide and 6-mm-long arms capable of an approximately 12-mm grasp) and were used in conjunction with thermal ablation or mechanical scraping of the tissue around the edges of the defect to achieve a more resilient seal. OTSC demonstrated a statistically significant successful closure rate for GI perforations and leaks (average $82 \%$ ) compared to that of fistulas (42.9\%), and long-term success of OTSC as a primary than a rescue therapeutic option ( $69 \%$ vs. $46.9 \%$, respectively, $\mathrm{P}=0.004)$ for managing $\mathrm{GI}$ perforations and leaks, as well (39). A systematic review concluded that OTS clips achieved successful closure rate of $51.5 \%$ in $\mathrm{GI}$ fistulae and $66 \%$ in $\mathrm{GI}$ anastomotic leaks ${ }^{(10)}$. OTS clips were used to close narrow perforation usually less than $1 \mathrm{~cm}$ and in cases of gastric ulcer perforations only as the stomach has a capacious lumen.

OverStitching is theoretically an optimum method of site perforation closure in gasric ulcer perforation only ( not duodenal ulcer) because it is the only true full thickness site perforation closure and performed endoscopically despite being a complex procedure. In this study, OverStitching was used in 5 
patients (10\%) who under endoscopic management. The procedure began with de-epithelialization of the edges of the site perforation using diathermy cautery before applying the OverStitching system. We did not experience post-OverStitch gastric leak. It is usually used in gastric ulcer perforation with size $1-2 \mathrm{~cm}$.

In this study, we used a fully covered stent in 30 patients (60\%) (Mega stent, Taewoong Medical Industries, Gyeonggi-do, South Korea) ultra large and long (length: $24 \mathrm{~cm}$, diameter: $36 \mathrm{~mm}$ ) stent in both gastric \& duodenal ulcer perforations. We did not experience any complication with Mega stent, particularly migration, thanks to the design of Mega stent that fits well with reduction of migration. It completely covers the whole perforation site and its lower end rests in second part of the duodenum ${ }^{(11)}$. The reported migration incidence of FCSEMS is twice that of partially covered stents (26\% vs. $13 \%){ }^{(12)}$.

This study has some limitations. The small sample size that may not give powerful statistical conclusions. Exclusion of patients with age below 18 years old is another limitation. Regarding the deepithelization of the edges of fistula either for OTSC or OverStitch, there was not a single method, and it was up to the endoscopist to use argon plasma laser or mechanical scrapping of the edges. Moreover, this study showed only 3-months follow-up period. The strength of the present study is being a randomized controlled trial and comparing different endoscopic interventions on one hand with the surgical intervention on the other hand.

\section{Conclusion}

combined endoscopic \& interventional radiology can effectively manage acute perforated peptic ulcer without need for general anesthesia, within short time, in high risk surgical patients with low incidence of morbidity \& mortality.

\section{Abbreviations}

Ppu: perforated peptic ulcer

EG: endoscopic group

SG: surgical group

FCSEMS: fully covered self-expanded metallic stent

OTSC : Over-The-Scope Clipping

\section{Declarations}

Availability of data \& materials: All data generated during this study are included in this published article and its supplementary information files. Further minor datasets are available from the corresponding author on reasonable request. 
Contributions :The manuscript has been read and approved by all the authors; the requirements for authorship have been met; each author believes that the manuscript represents honest work. Said negm, Ahmed Farag and Ahmed Shafiq were directly involved in the entire procedure and designed the clinical case. Adel Ismail, Mahmoud Yassin and Bassam Moussa screened the literature. Mazoun Al Alawi, Mohamed abozied, Taha Abdelkader and Yasser A.Orban were responsible for data acquisition and creation of supplementary information files. Hatem Mohamed, Said Negm, Ahmed Farag, Adel Ismail, Mahmoud Yassin, Bassam Moussa and Mohamed Abozied were involved in manuscript preparation. Yasser A Orban and Mazoun Al Alawi were involved in critical revision, editing and reviewing of the paper. All authors read and approved the final manuscript.

Consent for publication: Obtained.

Competing of interests: The authors declare that they have no competing interests.

Funding :No funding to declare.

\section{References}

1. Lanas A, Chan FKL. Peptic ulcer disease. Lancet. 2017;390:613-24.

2. Chung KT, Shelat VG. Perforated peptic ulcer - an update. World JGastrointest Surg. 2017;9:1-12.

3. Sivaram P, Sreekumar A. Preoperative factors influencing mortality and morbidity in peptic ulcer perforation. Eur J Trauma Emerg Surg. 2018;44:251-7.

4. Jensen DM, Ohning GV, Kovacs TO, et al., Doppler endoscopic probe as a guide to risk stratification and definitive hemostasis of peptic ulcer bleeding. Gastrointest Endosc.2016;83:129-36.

5. Das R, Sureshkumar S, Sreenath GS, et al., Sequential versus concomitant therapy for eradication of Helicobacter Pylori in patients with perforated duodenal ulcer: A randomized trial. Saudi $J$ Gastroenterol. 2016;22:309-15.

6. Manno M, Mangiafico S, Caruso A, et al., First-line endoscopic treatment with OTSC in patients with high-risk non-variceal upper gastrointestinal bleeding:preliminary experience in 40 cases. Surg Endosc. 2016;30:2026-9.

7. Nelms DW, Pelaez CA. The Acute Upper Gastrointestinal Bleed. Surg Clin North Am. 2018;98:104757.

8. Spahn DR, Bouillon B, Cerny V, et al., The European guideline on management of major bleeding and coagulopathy following trauma: fifth edition. Crit Care. 2019;23:98.

9. M. Clinton Miller, Ph.D, Rebecca G. Knapp: Clinical epidemiology and biostatistics, published by Williams \& Wilkins, Maryland: 3rd edition 1992.

10. Kobara H, Mori H, Nishiyama N, et al., Over-the-scope clip system: A review of 1517 cases over 9 years. J Gastroenterol Hepatol. 2019;34(1):22-30. 
11. Basha J, Appasani S, Sinha SK, et al .,Mega stents: a new option for management of leaks following laparoscopic sleeve gastrectomy. Endoscopy. 2014;46 Suppl 1 UCTN:E49-50.

12. van Boeckel PG, Sijbring A, Vleggaar FP, et al., Systematic review: temporary stent placement for benign rupture or anastomotic leak of the oesophagus. Aliment Pharmacol Ther. 2011;33(12):1292301.

\section{Tables}

Table 1. Characteristics of the patients. 


\begin{tabular}{|c|c|c|}
\hline Sex & $\mathrm{N}$ & $\%$ \\
\hline Male & 69 & 69 \\
\hline Female & 31 & 31 \\
\hline \multicolumn{3}{|l|}{ Blue dye test postoperative } \\
\hline Negative & 93 & 93 \\
\hline Positive & 7 & 7 \\
\hline \multicolumn{3}{|l|}{ Need for general anesthesia } \\
\hline No & 44 & 44 \\
\hline Yes & 56 & 56 \\
\hline \multicolumn{3}{|l|}{ Success to close the perforation } \\
\hline No & 7 & 7 \\
\hline Yes & 93 & 93 \\
\hline \multicolumn{3}{|l|}{ Mortality } \\
\hline No & 97 & 97 \\
\hline Yes & 3 & 3 \\
\hline \multicolumn{3}{|c|}{ Post-operative decrease in CRP \&amp; WBC count } \\
\hline No & 7 & 7 \\
\hline Yes & 93 & 93 \\
\hline \multicolumn{3}{|l|}{ Postoperative complication } \\
\hline No & 59 & 59 \\
\hline Yes & 41 & 41 \\
\hline \multicolumn{3}{|l|}{ Postoperative complications } \\
\hline No complications & 59 & 59 \\
\hline Fever & 21 & 21 \\
\hline Pneumonia & 5 & 5 \\
\hline Leak & 7 & 7 \\
\hline Abdominal abscess & 3 & 3 \\
\hline Renal failure\& incisional hernia & 2 & 2 \\
\hline Incisional hernia & 3 & 3 \\
\hline
\end{tabular}


Table2. Operative time and postoperative hospital stay.

\begin{tabular}{llll} 
& Mean \pm SD & Median(IQR) & Maximum:Minimum \\
\hline Age years & $43.86 \pm 14.46$ & $44(34: 50)$ & $85: 20$ \\
\hline operative time in minutes & $35.68 \pm 19.11$ & $30(17.5: 50)$ & $80: 10$ \\
\hline postoperative hospital stay in days & $4.45 \pm 3.89$ & $5(1: 7)$ & $20: 0$
\end{tabular}

Table 3. Chi-square test used to compare groups *Exact test correction 


\begin{tabular}{llll} 
& EG & SG & P value \\
\cline { 1 - 3 } Sex & N(\%) & N(\%) & \\
\cline { 1 - 3 } Male & $33(66)$ & $36(72)$ & \multirow{2}{*}{0.517} \\
\cline { 1 - 3 } Female & $17(34)$ & $14(28)$ & \\
\cline { 1 - 3 }
\end{tabular}

\section{Blue dye test postoperative}

$\begin{array}{lll}\text { Negative } & 48(96) & 45(90)\end{array} * 0.436$

\section{Need for general anesthesia}

$\begin{array}{lll}\text { No } & 44(88) & 0(0)\end{array}<0.001$

Success to close the perforation

\begin{tabular}{|c|c|c|c|}
\hline No & $2(4)$ & $5(10)$ & *0.436 \\
\hline Yes & $48(96)$ & $45(90)$ & \\
\hline \multicolumn{4}{|c|}{ Mortality } \\
\hline No & $50(100)$ & $47(94)$ & \multirow[t]{2}{*}{$* 0.242$} \\
\hline Yes & $0(0)$ & $3(6)$ & \\
\hline
\end{tabular}

\section{Post-operative decrease in CRP \&amp; WBC count}

$\begin{array}{lll}\text { No } & 2(4) & 5(10)\end{array} * 0.436$

\section{Postoperative complication}

\begin{tabular}{llll} 
No & $38(76)$ & $21(42)$ & 0.001 \\
\cline { 1 - 2 } Yes & $12(24)$ & $29(58)$ &
\end{tabular}

\section{Postoperative complications}

\begin{tabular}{llll}
\hline No complications & $38(76)$ & $21(42)$ & 0.001 \\
\hline Fever & $10(20)$ & $11(22)$ & 0.806 \\
\hline Pneumonia & $0(0)$ & $5(10)$ & $\star 0.056$ \\
\hline Leak & $2(4)$ & $5(10)$ & $\star 0.436$ \\
\hline Abdominal abscess & $0(0)$ & $3(6)$ & $\star 0.242$ \\
\hline Renal failure\& incisional hernia & $0(0)$ & $2(4)$ & $\star 0.495$
\end{tabular}


Table 4. Mann-Whitney U test used to compare groups.

\begin{tabular}{llll} 
& EG & SG & P value \\
\hline & Median(IQR) & Median(IQR) & \\
\hline Age years & $47(41: 50)$ & $36(27: 54)$ & 0.014 \\
\hline operative time in minutes & $17.5(15: 20)$ & $50(45: 60)$ & $<0.001$ \\
\hline postoperative hospital stay in days & $1(1: 2)$ & $7(6: 8)$ & $<0.001$
\end{tabular}

\section{Figures}

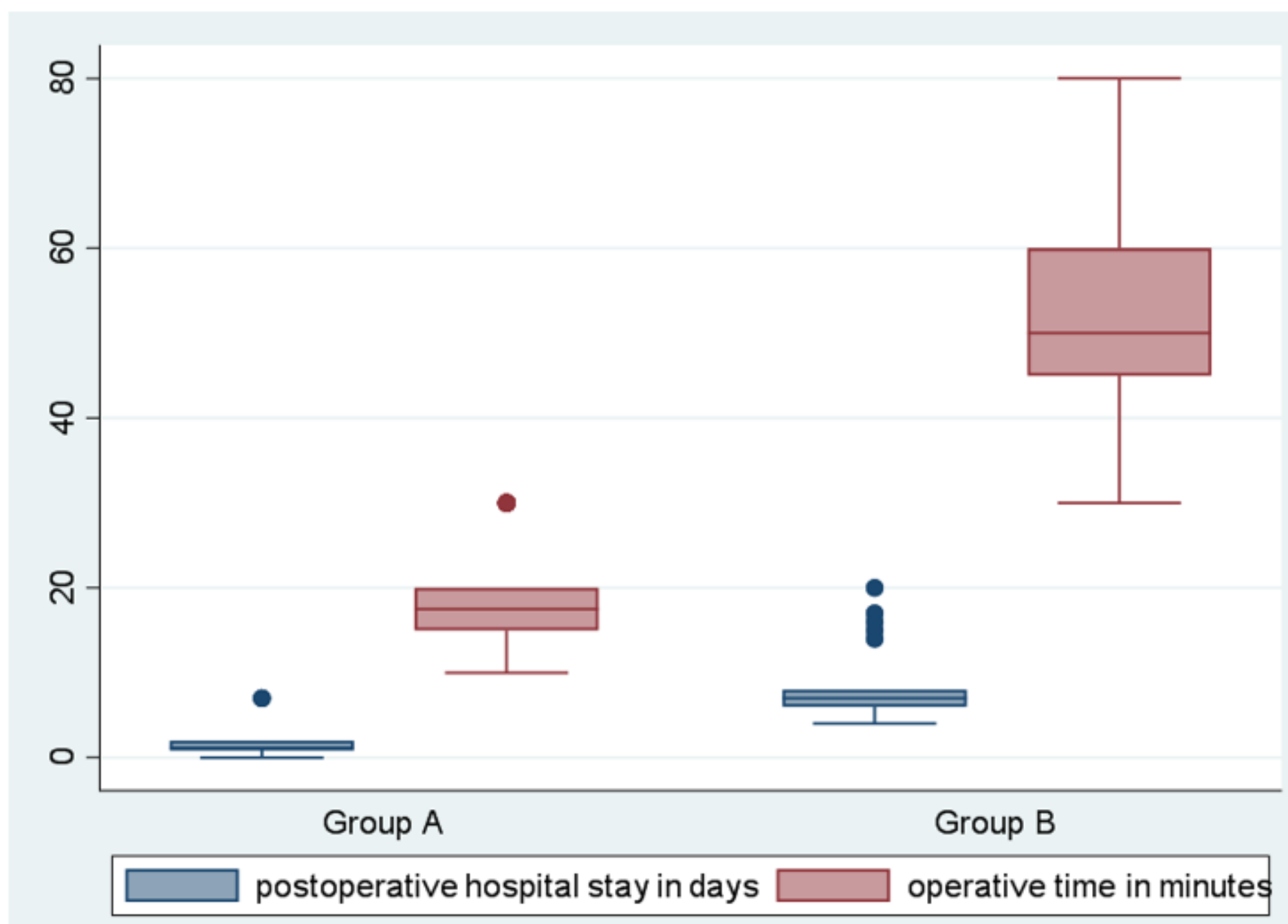

Figure 1 
Box plot to compare operative time and hospital stay between group A (EG) Group B (SG).

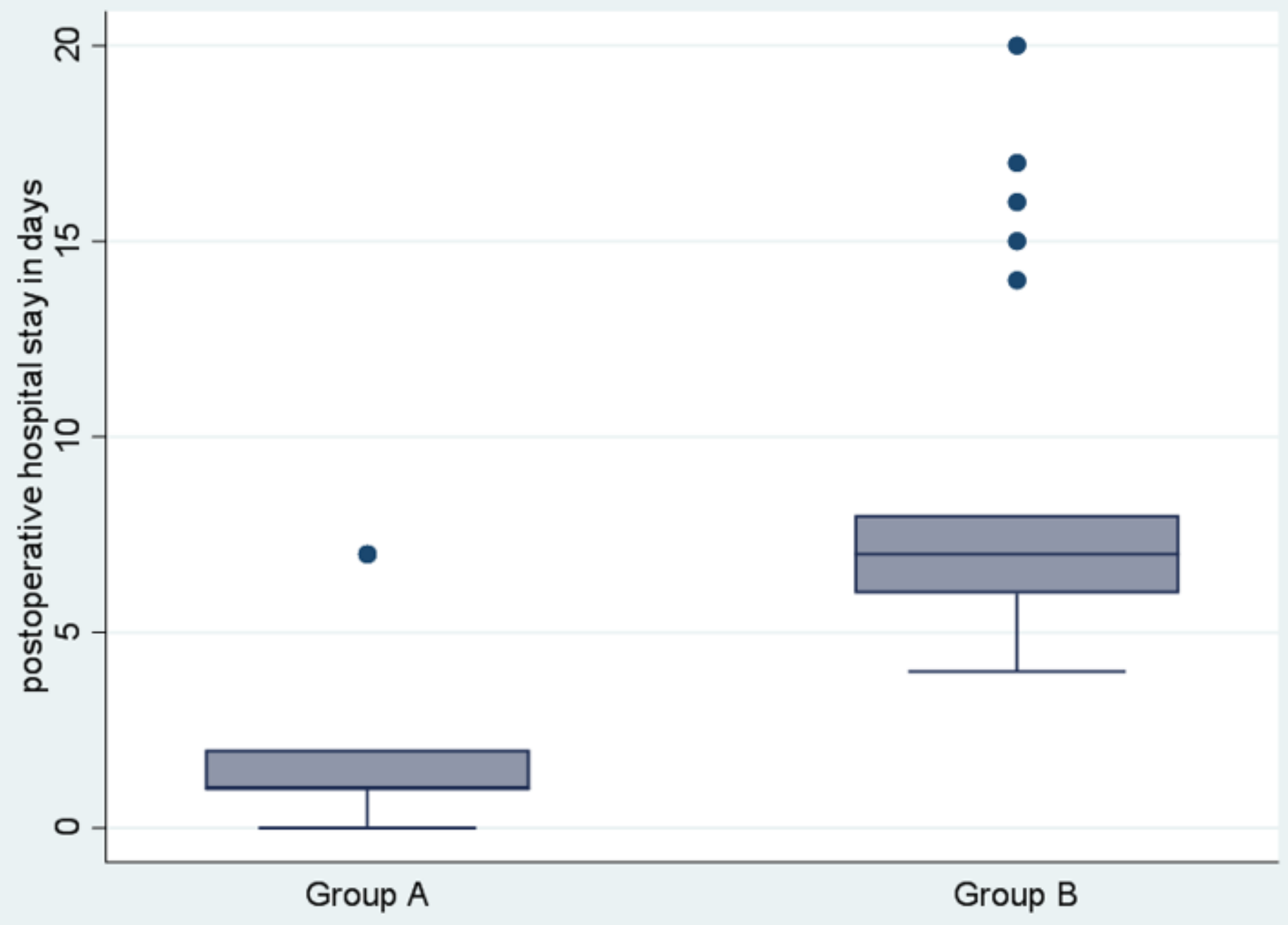

Figure 2

Box plot to compare operative time between Groups A (EG) and B (SG). 


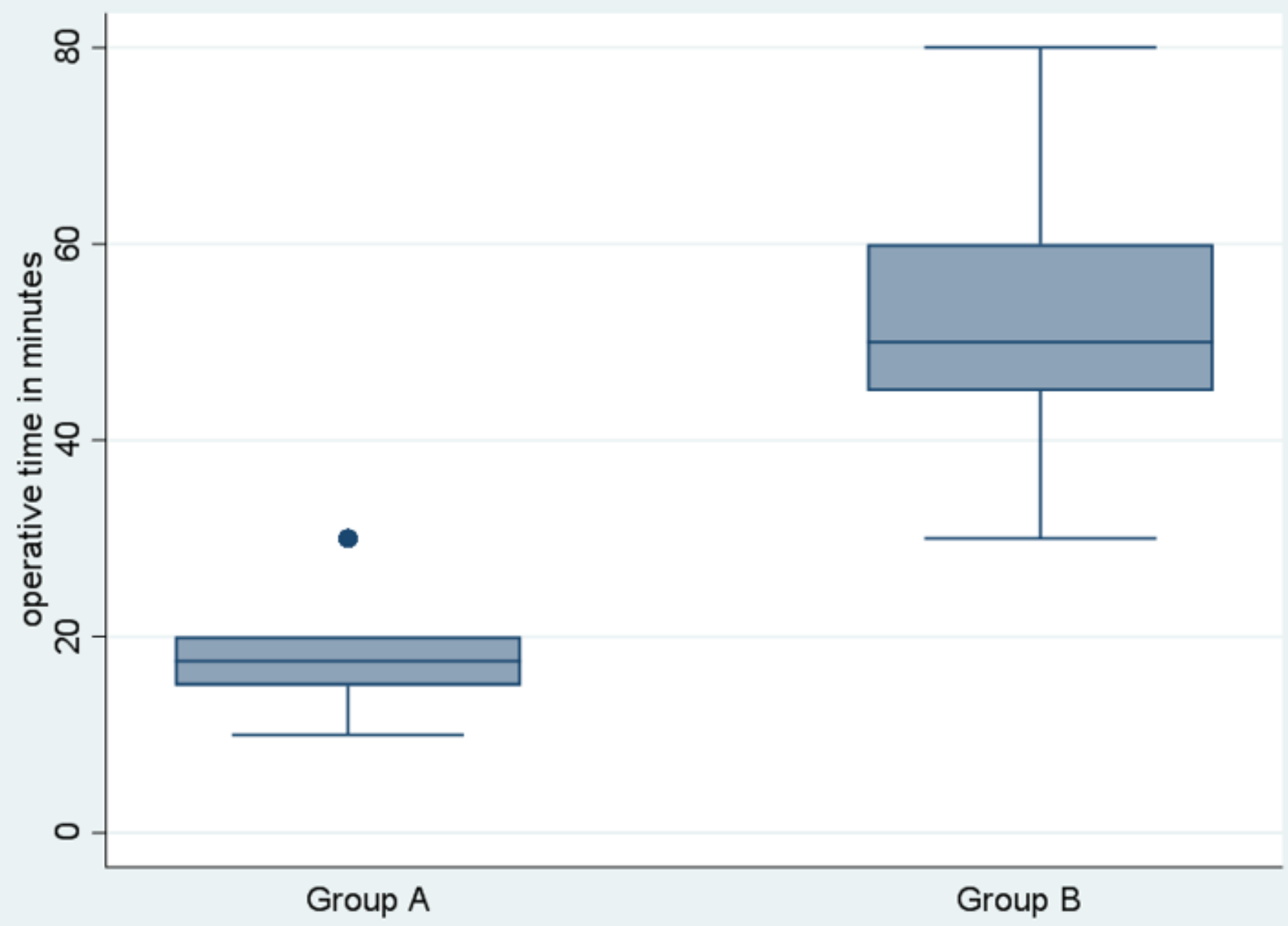

Figure 3

Box plot to compare operative time between groups $A(E G)$ and $B(S G)$. 


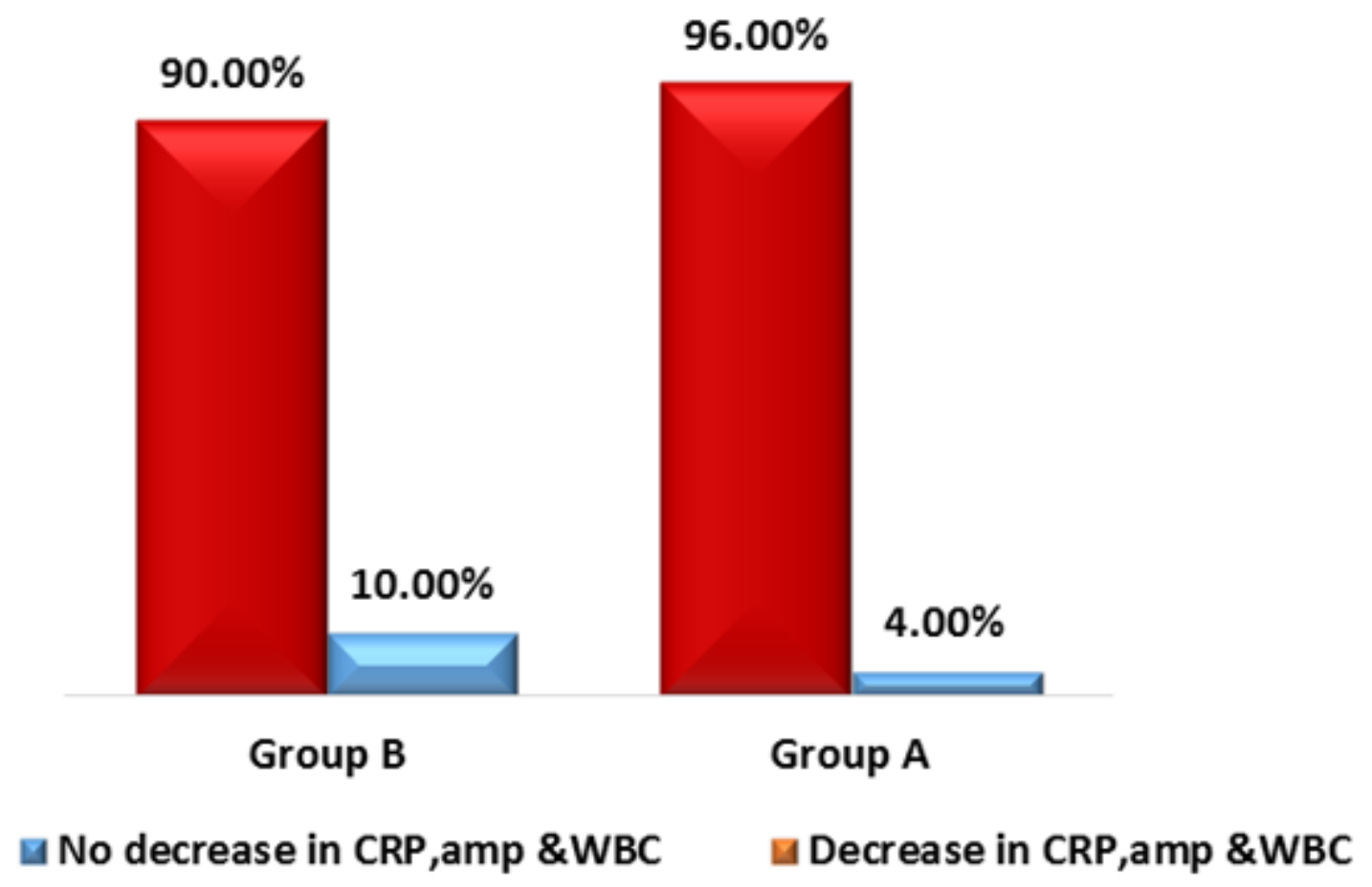

Figure 4

Decrease in CRP \& WBCs in group $A(E G)$ \& group $B(S G)$. 


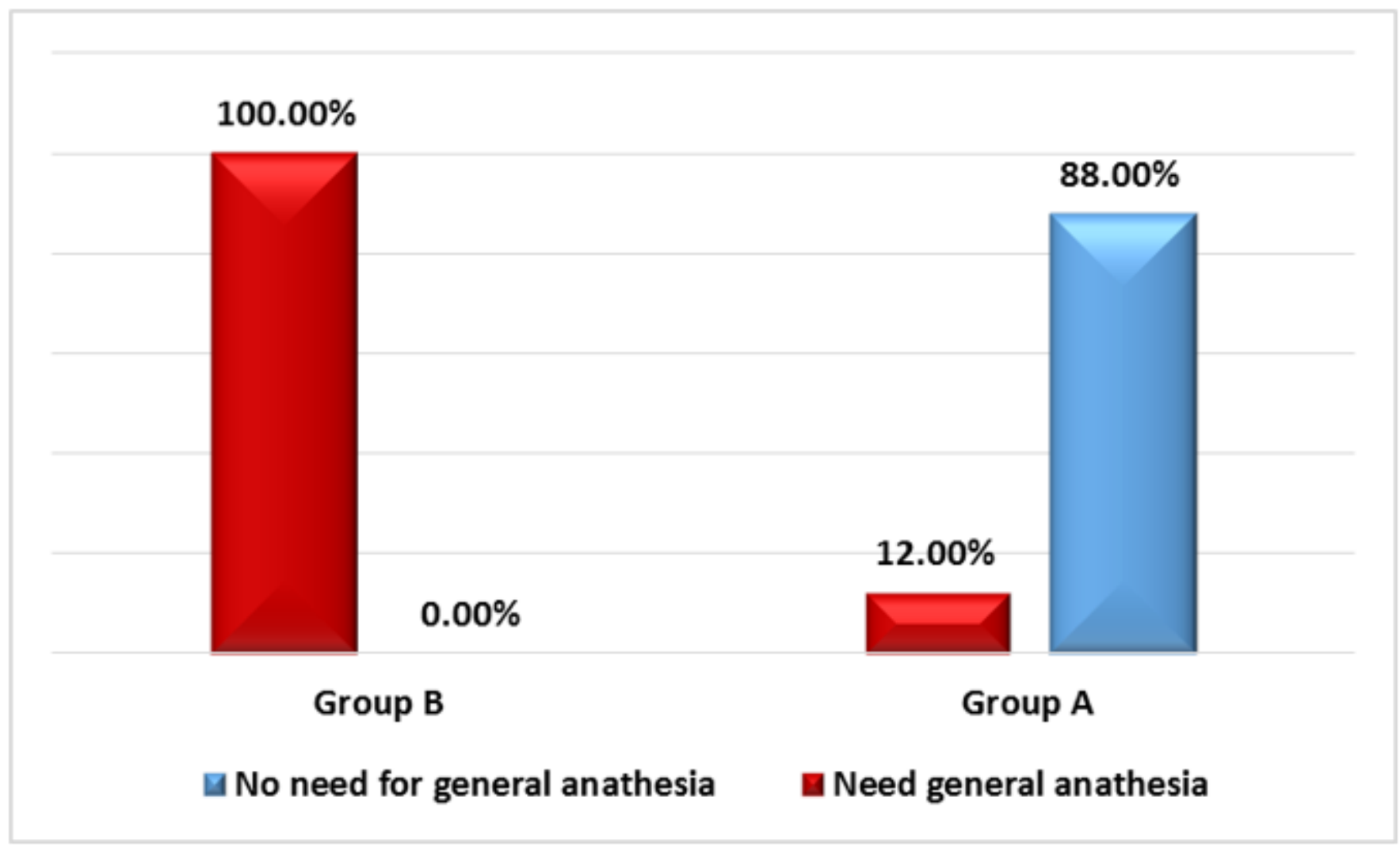

Figure 5

Need for general anathesia in group A ( EG) \& group B ( SG). 